\title{
45 ANOS DE GEOGRAFIA
}

JORGE GASPAR ${ }^{1}$

Em Outubro de 2005 completam-se 45 anos de convívio, académico e humano, entre o Carlos Alberto Medeiros e o autor deste apontamento. Um tão longo período em qualquer tipo de vida partilhada e muito em particular numa Universidade-seja ela onde for-passa por momentos melhores e piores. Partindo desta ideia que faz parte da sabedoria convencionada, olhei para trás e fiquei de algum modo surpreendido por não encontrar esses 'piores'. A minha relação com o Carlos Alberto foi sempre boa, o que não significa esfuziante, mas foi serena, sempre em consolidação, mantendo-se vivo o sentimento da amizade. Creio que isso se ficou a dever muito a duas coisas: ao temperamento do Carlos Alberto e ao intenso convívio, aberto e franco, dos nossos primeiros anos na Universidade.

Claro que o facto de sermos duas pessoas com gosto pelo humor bem cultivado, ajudou, e continua a ajudar, bastante.

Nestas circunstâncias, senti-me na obrigação de trazer para este apontamento alguma memória com sentido de futuro, em torno de temas que além de fazerem parte das grandes mudanças operadas na Geografia de Portugal ao longo destes 45 anos, de algum modo estiveram presentes nas preocupações geográficas de homenageado e homenageante.

Assim, além do memoriar brevemente os últimos 45 anos da nossa estadia/passagem no CEG, com ênfase para o tempo da iniciação, elegi, afectivamente, quatro temas, por fazerem parte do nosso passado comum, sob diferentes aspectos, mantendo grande actualidade para a Geografia. E em qualquer desses quatro domínios tão distintos, esperam-se novos contributos do Carlos Alberto Medeiros. É necessário um olhar renovado dos geógrafos sobre a Alimentação, o Futebol, a África e a Geografia Nova, em construção.

Releve-me o acidental leitor, assim como o primeiro destinatário, todo e qualquer despropósito.

1 Professor Catedrático da Faculdade de Letras, Universidade de Lisboa. Investigador do Centro de Estudos Geográficos da Universidade de Lisboa. E-mail: jgaspar@fl.ul.pt 
Neste percurso de 45 anos duas entidades centrais marcaram as nossas vidas e deram-lhes um sentido de continuidade: uma instituição e uma personalidade. O Centro de Estudos Geográficos (CEG) e o seu fundador, o Professor Orlando Ribeiro.

Cabe aqui notar que o CEG, fundado em 1943, tem uma história com duas metades, a da direcção Orlando Ribeiro e a posterior, sensivelmente com a mesma duração. Neste já longo período de existência - facto assinalável para uma instituição de investigação universitária quase informal - deve enfatizar-se a continuidade de funcionamento, sem que isso tenha posto em causa as rupturas necessárias, organizativas e epistemológicas, decorrentes de um crescimento acentuado no último quartel do século XX.

Mantém-se, entretanto, a fragilidade institucional: o CEG não tem personalidade jurídica nem administrativa, facto para muitos estranho, tendo em conta a continuidade, a solidez da produção científica e a afirmação na comunidade científica, nacional e internacional ${ }^{2}$. Esta fragilidade ou informalidade, permitiu mesmo a 'usurpação' do título da sua revista, com 4 dezenas de anos de publicação contínua, apenas porque não tinha o título registado (formalidade não exigível para revistas científicas de âmbito universitário à época da sua criação nos anos 60). Após negociações cordiais com representantes da instituição editora de outra Finisterra, foi-nos 'concedido' manter a designação Finisterra - Revista Portuguesa de Geografia.

O problema da afirmação institucional do CEG prende-se com um traço da personalidade do seu fundador, transmitido à maior parte dos seus discípulos: manter a independência face aos poderes, dos mais conspícuos aos mais crípticos. Se este posicionamento tem custos, também tem retornos. Creio que o Carlos Alberto, assim como eu próprio ou o Brum Ferreira, preferimos assim.

Nestes 45 anos o CEG cresceu a partir de uma pequena estrutura que já consideraram de 'natureza familiar', decerto importante para a afirmação e consolidação do primeiro quarto de século, mas que depois precisou de crescer - situação bem avaliada por Ilídio do Amaral, que a partir de meados dos anos 60 lhe imprimiu um novo ritmo e o preparou para um crescimento seguro e qualificado.

Hoje o CEG tem uma posição destacada a nível mundial, com uma estrutura diversificada que abrange os grandes domínios da Geografia, actualizados e inseridos em mais de duas dezenas de redes internacionais de investigação e de desenvolvimento.

E que melhor argumento para a apresentação do CEG como instituição de grandes méritos, traduzidos na sua robustez, qualidade científica e pluralidade

2 O CEG tem cerca de 60 investigadores, dos quais mais de metade com doutoramento, uma revista científica com projecção internacional, várias séries de publicações e uma classificação reiterada, de Excelente, conferida por júris exclusivamente internacionais nomeados pela Fundação para a Ciência e Tecnologia (FCT). Cf. www.ceg.ul.pt e www.fct.pt 
de orientações, do que uma continuidade geracional, tanto na gestão administrativa como na científica: desde há 3 anos sob a direcção de Diogo de Abreu e de uma equipa renovada e jovem, o CEG mantém-se fiel à sua história, isto é, actualiza-se continuamente, afirmando-se no espírito do tempo, com os mesmos 'desaconchegos' oficiais.

A outra face da Geografia na Universidade de Lisboa corresponde aos cursos e aos alunos - a primeira razão de ser da nossa existência enquanto geógrafos e professores. Também aqui, esses 45 anos foram uma caminhada gratificante, traduzida no crescimento de pouco mais de duas dezenas de alunos em 1965, a cerca de oito centenas em 2005.

As formações facultadas por licenciaturas e mestrados têm sido renovadas para responder às procuras e, tanto quanto os indicadores de desempenho permitem avaliar, as soluções têm tido resposta positiva - a diversificação e o incremento da empregabilidade da Geografia têm-se verificado e hoje, por todo o País, nos mais diversos domínios da actividade económica, encontramos geógrafos, afirmando-se muitos dos nossos alunos, quantas vezes de forma surpreendente, ao ponto de nos levar a pensar como fomos talvez demasiado exigentes ou excessivamente cautelosos nas avaliações.

Os geógrafos, em todo o mundo, têm tendência para atitudes críticas face às intervenções no território resultantes de políticas desacertadas, mas também, porque conhecendo os mecanismos de transformação (produção, ordenamento, reciclagem) desses territórios, tendem a olhar o futuro com esperança: é a Lição da Geografia. Por isso, estou convicto que se nestes 45 anos a Ciência Geográfica teve os progressos que teve em Portugal, conseguindo um lugar no seu palco internacional, foi fundamentalmente porque o País também mudou, no mesmo sentido.

\section{O TEMPO DA INICIAÇÃO}

A Licenciatura em Geografia, que frequentámos entre 1960 e 1965, tinha sido pensada principalmente por Orlando Ribeiro, como uma preparação transversal, a Geografia como Ciência da Terra, mas no encontro das Ciências Humanas e das Ciências Naturais. Assim, além da Geografia, tinham grande peso no currículo a Zoologia, a Botânica, a Geologia e a Mineralogia, como a História e a Etnologia. Por sua vez, na componente geográfica, verificava-se um equilíbrio entre a Geografia Física e a Geografia Humana. A síntese deveria ser feita na Geografia Regional, na boa tradição possibilista e Francesa.

De facto, a síntese, a integração e o cruzamento de saberes, tinha lugar na prática do trabalho de campo, um dos pontos fortes da Licenciatura, embora praticado com profundidade diversa, de disciplina para disciplina.

Os momentos mais exaltantes que vivi na Licenciatura foram as excursões e as visitas de estudo, sobretudo as que duravam vários dias e em que era possível prolongar as discussões para além do pôr do sol. Assim conhecemos o País de Norte a Sul. 
Mesmo em trabalhos de inquérito regulares, como o que levámos a cabo com João Evangelista no âmbito da Geografia Humana II no mercado semanal de Caldas da Rainha ou em excursões orientadas para o planeamento regional, como as que promoveu Correia da Cunha no âmbito da sua cadeira de Geografia Aplicada, nunca deixámos de equacionar questões sobre a paisagem, sobre o clima, a geomorfologia ou a cobertura vegetal.

Mas, como em todas as épocas, muito do que se aprende na Universidade é fora das aulas e do sistema formal de aprendizagem. É nas iniciativas das associações de estudantes, nas actividades proporcionadas por outras organizações e, sobretudo, nas discussões informais em torno de múltiplas questões - as do curso e as do 'mundo exterior'.

Nos meus primeiros anos de Universidade também aprendi muito no convívio com Carlos Alberto Medeiros e António de Brum Ferreira, não só porque tínhamos as 'antenas' orientadas para o País e para o Mundo, o que facultava temas de discussão com dimensões geográficas, mas também pela riqueza que proporcionava a troca de experiências vividas, entre dois micaelenses e um lisbonense, e que iam do clima à história, passando pela literatura e pelos comportamentos societais.

Hoje tenho pena de uma oportunidade perdida, a de não ter conhecido a Ilha de São Miguel com os meus colegas, nesses primeiros anos da nossa experiência académica; mas desde o liceu que a Europa, o que estava para lá dos Pirinéus, me fascinava e me atraía irresistivelmente o que, no fundo, também foi uma forma de recolher novos temas e prolongar as conversas dos 9 meses escolares.

Sem nostalgia e arredando qualquer mal entendido que pudesse emergir do implícito paralelismo, porque não me sinto habilitado a comparar o ambiente académico do início dos anos 1960 com o do início do século XXI, quero afirmar apenas como então tudo se passava num grande espírito de colaboração, de ajuda mútua e, consequentemente, de partilha e enriquecimento de todos.

Por isso, também foi com naturalidade que cada uma dos três foi procurando um ramo a privilegiar na Geografia o que nas nossas discussões já era defendido como o mais importante e decisivo: o Brum Ferreira orientando-se para a Geografia Física, o Carlos Medeiros para a Geografia Regional e eu, privilegiando o triângulo social-económico-urbano.

Ajuda fundamental nessa aprendizagem 'extra-curricular' era pois o que proporcionavam os tempos livres, o que sobrava dos dias, das semanas, dos trimestres escolares. Também por aí se consolidava a formação dos jovens geógrafos.

\section{ALIMENTAÇÃO E COMIDAS}

Quando nos conhecemos em 1960, caloiros entre duas faculdades, a de Ciências, na Politécnica, e a de Letras, na Cidade Universitária, tínhamos que 
resolver uma questão vital: as refeições. Optámos inicialmente pela cantina do Instituto Superior de Estudos Ultramarinos, que ficava então no Príncipe Real, mesmo junto à Faculdade de Ciências, onde as aulas começavam às $8 \mathrm{~h}$ da manhã, quatro dias por semana (no outro dia as aulas eram na Faculdade de Letras). Mas sempre que calhava, lá íamos a umas tascas, na busca dos petiscos, em que eu seria o guia, centrando-se a conversa, frequentemente, na nostalgia das coisas boas dos Açores - foi aí que ouvi, pela primeira vez, falar nas cracas, na alcatra, nos charritos de Rabo de Peixe, preparados de certa maneira.

Mas a aprendizagem da alimentação, boa e portuguesa, far-se-ia também ao longo do curso. E de novo, o mestre era o mesmo, Orlando Ribeiro, embora outros professores tivessem também preocupações com os comeres e beberes, com realce para o João Evangelista, com grande capacidade de evocação dos produtos de qualidade e do seu bom resultado quando em ordem de chegar ao prato.

As excursões constituíam a oportunidade bem aproveitada, em jantares e picnics, para se saborear e discorrer sobre alimentação. A propósito, vinham sempre hábitos e costumes de outras latitudes, as 'Áfricas', o Brasil, Goa, eram as referências dominantes, mas, na Europa, Espanha e França, também podiam vir à conversa.

Noutras ocasióes a alimentação chegava pela via do ensino - a difusão das plantas alimentares, os tabus alimentares das diferentes civilizações, a Geografia da Fome, de Josué de Castro, via João Evangelista, ou os hábitos mais estranhos de sociedades ameríndias ou africanas, através das lições de Jorge Dias.

Da alimentação, obviamente, também fazia parte o vinho, e o beber entrava na tradição excursionista - geográfica, não só em Portugal, mas um pouco por toda a Europa e Américas, como se viria a verificar mais tarde.

E foi neste convívio, 'estudo e banquete', que também consolidámos conhecimentos e amizades. Penso que aqui reside uma lição, um tema a recuperar na prática dos trabalhos geográficos, até porque aí, de forma crescente, têm, se quiserem, contributos relevantes a oferecer à sociedade.

Foi no tempo da nossa primeira aprendizagem em Geografia que teve início uma grande mudança nos hábitos alimentares dos portugueses, correlativa do processo de urbanização: a substituição do azeite pelos óleos e margarinas, a generalização da batata frita, a regressão das sopas e dos vegetais cozinhados, o consumo de carne de produção intensiva (frango, porco, vaca), a difusão do automóvel e da restauração rodoviária - ainda prelúdios da 'mauvaise-bouffe' e do 'fast-food'.

Mas nas pensões de província que frequentávamos amiúde, ainda nos serviam os pratos de longa confecção, com o gosto dos produtos tradicionais (as batatas, os feijões, o grão de bico, as vagens, as couves, o porco de salgadeira, a criação de capoeira ou coelheira...) e, à sobremesa, a marmelada com o flamengo, o arroz doce, o leite creme, mais tarde substituídos pelas mousses de chocolate, as babas de camelo, os doces da avó, os molotofes, e os pudins 
flã... até que tudo passou a chegar, já não do pacote para a cozinha mas da geladeira para a mesa...

Felizmente, com a idade, fomos diminuindo as quantidades e o aumento de rendimento, em correlação com o País, permite-nos aceder a outros locais que, bem escolhidos, constituem outro patamar, o da gastronomia, embora nem sempre de qualidade garantida e dificilmente satisfazendo uma boa relação qualidade-preço.

Gostaria de exortar aqui o Carlos Alberto Medeiros e todos os geógrafos de boa vontade e boa comida, a ajudarem na abertura de uma área que será fundamental no futuro da Geografia: a alimentação. Mais! A boa alimentação deve ser um instrumento para o desenvolvimento sustentável: a estratégia sueca neste domínio tem um capítulo dedicado à alimentação! É óbvio, mas cá ainda não reparámos.

Além do desenvolvimento é também o ordenamento do território que está em causa-só pela qualidade alimentar poderemos recuperar e valorizar a produção agrícola e pecuária, viabilizando assim o cultivo de terras hoje abandonadas ou em vias de o ser. Por outro lado, só aprendendo a comer bem, com qualidade, poderemos valorizar as produções verdadeiramente frescas, como são as de proximidade - e há tanta terra agrícola abandonada na periferia e até no interior das novas aglomerações urbanas...

\section{FUTEBOL E GEOGRAFIA}

Não é de agora a centralidade do futebol na vida dos portugueses, nem tão pouco o seu carácter inter-classista.

Embora introduzido em Portugal por jovens provenientes de classes sócio-económicas mais privilegiadas, o futebol muito depressa se popularizou, atingindo rapidamente as populações proletárias sem, todavia, ter afastado os outros grupos sociais. Ainda hoje é assim.

Creio que terei sido pioneiro, entre os geógrafos, na eleição do tema futebol como interessante para as abordagens geográficas. Num artiguinho que publiquei na revista Brotéria, em 1970, procurei evidenciar, entre outros aspectos da geografia do futebol em Portugal, uma relação estreita entre industrialização e prática do futebol. Não só a hierarquia dos pólos futebolistas se aproximava, ao ponto de quase coincidir, da hierarquia dos pólos de desenvolvimento industrial, como os principais 'alfobres' ('canteras') do futebol português de então, correspondiam aos centros industriais mais 'puros': Barreiro, no Sul, e Matosinhos, no Norte.

Noutros artigos, já de 1981 e 1982, feitos em colaboração com José Manuel Simões, J. Honório e F. Honório, dava-se conta de algumas alterações naquele panorama mantendo-se, em certa medida, alguns pressupostos do 'modelo explicativo', que entretanto perdera 'pureza'. Todavia, a emergência do domínio 
do Norte, nomeadamente do Entre Douro e Cávado em relação a Lisboa, indiciava, em certa medida, o declínio industrial da Área Metropolitana de Lisboa e a especialização do espaço urbano-industrial do Noroeste.

Entretanto alteraram-se estas relações e, como em outros domínios da vida social, económica e cultural do país, a geografia do futebol é mais determinada pela procura do que pela oferta, sendo por vezes pouco claras as bases de apoio, nomeadamente as de carácter financeiro.

Também do lado do futebol se manifestou forte empatia entre nós, o Carlos Alberto e eu, embora simpatizantes de clubes diferentes, comungamos desse 'mal nacional' que é a adesão apaixonada ao 'desporto rei'. Seja-me permitida uma pequena incon-fidência, já que o júbilo que ela transporta compensa o risco de insensatez da revelação: soube do próprio homenageado que o futebol é agora um dos seus temas eleitos na investigação. Em boa hora! Precisamos de novas perspectivas sobre um tema que ultimamente tem inflamado muitos portugueses, por vezes com muita falta de senso, tanto do lado dos bempensantes como dos outros, a grande maioria dos portugueses.

Claro que há a loucura das aquisições de jogadores que se multiplicam, os estádios desnecessários que se edificaram, além da insuportável promiscuidade de interesses e de processos que invadiram a gestão dos clubes e das equipas (hoje realidades distintas), com prejuízos a todos os níveis, em que a corrupção dos valores fundamentais da nossa sociedade não é despiciendo. Mal vai um País onde se privatizam os serviços fundamentais (água, educação, saúde, segurança social) e se municipalizam os clubes de futebol; onde se desinveste na educação e na saúde e se investe no futebol...

Mas, pelo menos, tem havido retorno, e o desempenho do futebol nacional tem sido notável. Em nenhum outro domínio Portugal está nos 10 primeiros lugares do ranking mundial... Com que custos? É isso que importa dilucidar, mas sem esquecer de individualizar os aspectos positivos: económicos, sociais, culturais.

Antes de mais importa notar que, como assinalei há 35 anos, o 'mundo' do futebol continua a ser interclassista, e hoje é também, na nova realidade sócio-cultural portuguesa, inter-racial. Em nenhuma outra actividade no nosso País estão tão bem resolvidas/dissolvidas as fricções raciais, tanto entre os jogadores, como entre jogadores e público. Note-se como as populações de origem africana, sobretudo as de imigrantes, tendem a concentrar-se na Área Metropolitana de Lisboa, contrariamente aos imigrantes dos Países de Leste e do Brasil, que se dispersam por todo o País - e a explicação releva decerto de questões que têm a ver com falta de aproximação entre africanos e caucasianos... Mas o futebol faz a excepção e de Norte a Sul, do Litoral ao Interior, encontramos jogadores oriundos de África e que não só são bem acolhidos, como desempenham um papel importante para o desenvolvimento do diálogo necessário.

O futebol, nas suas várias dimensões - económica social, desportiva e cultural - é um poderoso instrumento para a promoção da paz entre os povos, para 
a regeneração social a nível local, para a aproximação entre as comunidades multi-culturais, permitindo a um tempo o diálogo e a afirmação de cada identidade - veja-se a propósito só dois exemplos: o do clube português dos arredores de Paris, o ex-Lusitanos, hoje Saint-Maur e o Assiriska, um clube cuja base é a comunidade Assíria (sim, Cristãos Assírios, 2000 anos...) de Södertälja, a sul de Estocolmo

Ficamos pois a aguardar os novos contributos da Geografia que através do Carlos Alberto Medeiros vão por certo ajudar ao 'saneamento' multilateral do futebol, acabando com a nefasta diabolização de um desporto, que é uma das mais fecundas práticas sociais, além de poder contribuir para o robustecimento da nossa economia.

\section{IV. ÁFRICA NOSSA}

Em 1969 o Professor Ilídio do Amaral - o nosso primeiro professor de Geografia na Universidade de Lisboa, que nunca deixou de acompanhar e apoiar as nossas carreiras, tanto no ensino como na investigação - organizou uma viagem de estudo a Angola. A melhor viagem de estudo em que alguma vez participei: o itinerário bem escolhido, com múltiplas visitas a explorações agrárias, fábricas, instituições públicas, cidades, aldeias e, como não podia deixar de ser, a alguns dos marcos mais notáveis do ponto de vista geomorfológico.

Deu para conhecer a grandeza do País e muitos dos problemas em jogo, assim como a urgente necessidade de uma solução, que não seria senão a da independência. Todavia, os portugueses com quem contactei acreditavam na continuidade e que da solução militar sairia uma solução política a contento de todos...

Recordo também um convite para ficar, que me foi feito por um grande empresário residente. $\mathrm{Na}$ intimidade, formulei então o desejo, que transmitiria muitas vezes em conversas com amigos: gostaria de um dia trabalhar em Angola, mas quando fosse um País independente. Por isso, recusaria também uma proposta/sugestão do professor Orlando Ribeiro para ir leccionar na Universidade de Angola, no 'campus' de Sá da Bandeira, em grande parte vocacionado para a formação de professores.

O mesmo convite foi dirigido aos colegas Carlos e Isabel Medeiros que aceitaram, em boa hora para a Geografia, pois fizeram um trabalho de grande nível, tanto na pedagogia como na investigação científica. Para esse desempenho terá contribuído o facto de o Carlos Alberto ser já conhecedor das questões tropicais, pois frequentara o curso de Doutoramento de III Ciclo na Universidade de Bordéus, que concluiu com a respectiva Dissertação sobre um tema da Martinica. A investigação para a tese de doutoramento comportou, na boa tradição francesa, e também portuguesa, uma componente de trabalho de campo.

Assim, na senda do trabalho encetado pelos nossos dois mestres basilares, Orlando Ribeiro e Ilídio de Amaral, Carlos Alberto Medeiros viria a apresentar 
na Universidade de Lisboa, já em 1976, uma notável dissertação de Doutoramento sobre a Colonização das Terras Altas da Huila que mereceu os maiores elogios do júri e de outros especialistas de África.

Em 1972 encontrámo-nos, por acaso, em Luanda, o Carlos Alberto e a Isabel de visita, eu em trabalho de planeamento, um plano de recuperação de algumas áreas degradadas da capital Angolana, que comportava a reabilitação e realojamento do muceque da Samba Pequena. Convidei o casal para uma visita a pé pelo muceque, do que resultou uma sessão de trabalho de campo e, naturalmente, abordaram-se as questões relativas ao futuro de Portugal e de Angola - mal sabíamos que estávamos a menos de um ano de grandes mudanças... Para os geógrafos desprevenidos que se entusiasmavam, assim, no interior dos bairros pobres de Luanda, sem qualquer protecção ou precaução especial, aparentemente, qualquer mudança radical parecia distante. Talvez por isso, fazia sentido o trabalho no planeamento, a que eu me dedicava a partir de Lisboa e, ainda mais, o trabalho pedagógico e científico a que Carlos Alberto e a Isabel se dedicavam nas Terras da Huíla e no Litoral de Moçâmedes.

Reencontrámo-nos em Lisboa, na sequência das transformações políticas que o 25 de Abril de 1974 provocaram e que no Departamento de Geografia e no CEG foram a oportunidade para o fortalecimento e renovação do ensino e investigação: no nosso departamento não só não se verificaram as tristes cenas dos 'saneamentos' como ainda integrámos colegas vindos de Angola e de Moçambique. Claro que isso se ficou a dever aos antecedentes positivos, traduzidos na abertura e diálogo que dominou na escola informal que foi sempre o Centro de Estudos Geográficos de Lisboa.

Os acontecimentos subsequentes levaram-me a quase esquecer o projecto de juventude, de um dia ensinar em Angola; o Carlos Alberto concentrou-se na Geografia de Portugal e, sempre em crescendo, acabou por conceber e coordenar uma obra que desde há dezenas de anos falecia à Geografia Portuguesa: A Geografia de Portugal, agora no prelo.

Apenas a Isabel Medeiros manteria a 'chama Africana', continuando as suas pesquisas, consolidando o ensino de temas africanos não só nas licenciaturas de Geografia, como da recém criada Licenciatura em Estudos Africanos da Faculdade de Letras.

Mas 'uma andorinha não faz a Primavera' e é necessário que aconteça Primavera nas relações entre a África Lusófona e Portugal, processo para o qual os geógrafos podem oferecer contributos valiosos - pelo saber acumulado pela Geografia Portuguesa, pela natureza eminentemente geográfica que sempre revestirão essas relações, pois serão de trocas, e como todos os bons negócios, só fazem sentido com ganhos mútuos. 


\section{POR UMA GEOGRAFIA NOVA NUM PORTUGAL RENOVADO \\ - a obra aberta (under construction)}

Quantas novas geografias já conhecemos? De Mackinder a Peter Gould...

Essa recorrência da busca de uma geografia nova, ou renovada, deve merecer uma reflexão.

A geografia renova-se porque as sociedades e os territórios estão em permanente transformação. Cada período temporal constrói o seu próprio espaço, o que implica a necessidade de novas abordagens - novas teorias, novos métodos, novas geografias.

A procura de novas explicações e de novas descrições, vem dos nossos geógrafos do século XVI, manifesta-se na Universidade de Coimbra na sequência das reformas da viragem do Antigo Regime para a Era Liberal, está presente em Silva Telles e na formação da moderna geografia académica, no âmbito do Curso Superior de Letras que, poucos anos depois, originaria a Faculdade de Letras.

Lembro-me aqui das longas discussões com Carlos Alberto Medeiros e Brum Ferreira, em torno dos fundamentos teóricos da Geografia e do seu funcionamento no conspecto científico. Embora com balizas limitadas pela verdura do nosso estádio de aprendizagem, não deixavam de ser sessões muito acaloradas, à volta dos argumentos que suportavam as variantes do determinismo, de Ratzel a Huntington, ou do possibilismo de Vidal de la Blache a Pierre Gourou. Aqui detínhamo-nos à volta da pertinência do conceito de civilização, como 'chave da explicação em Geografia Humana' (O. Ribeiro...).

Um texto de Henry Baulig, lido e relido, alimentava a reflexão à volta do carácter científico da Geografia: partindo do seu questionamento, chegava-se, com o autor, à conclusão que também na dimensão metodológica, a Geografia tinha um carácter híbrido, desenvolvendo-se através de 3 vertentes - arte, técnica e ciência.

Outro tema recorrente nas nossas tertúlias centrava-se na validade da aplicação do conhecimento geográfico ao planeamento territorial e ao desenvolvimento regional. Este era de facto um ponto frágil da Geografia Portuguesa e do CEG em particular, que se tornava mais evidente no confronto com as notícias veiculadas por publicações francesas sobre as valências operativas da Geografia, assinaladas enfaticamente por autores consagrados como J. Tricart, P. George ou M. Philliponeau.

Claro que a necessidade aguça o engenho e, de facto, o reduzido número de geógrafos portugueses, centrados em Lisboa e em Coimbra, tinham suficientes solicitações para levar a cabo importantes e estimulantes estudos nas 'Províncias Ultramarinas', para os quais os recursos humanos disponíveis eram insuficientes. Desde o final dos anos 50 até ao 25 de Abril de 1974 muito do que de melhor se fez na investigação geográfica em Portugal, teve como objectivo temas coloniais, tanto na Geografia Física, como na Geografia Humana e, sobretudo, na Geografia Regional. 
Eu mantinha-me fora desse 'fascínio' pelas Investigações do Ultramar e, por outro lado, éramos incentivados para a tal Geografia Aplicada, necessária ao País, com tantos problemas por resolver ao nível regional e local, nos âmbitos urbano e rural.

Na sequência de iniciativas em países próximos como a França e a Espanha, discutia-se a necessidade de uma política regional, de 'pólos de desenvolvimento', de planos integradores ancorados em grandes projectos industriais ou agrários (o Plano de Rega do Alentejo esteve na ordem do dia desde finais dos anos 50), da definição de uma rede 'urbana', à semelhança das propostas francesas para uma 'armature urbaine'.

Entretanto, o País abrira-se ao comércio internacional, por um lado, com a integração na EFTA de que Portugal foi membro fundador, e, por outro lado, com um aprofundamento das relações preferenciais com os Estados Unidos da América e com a Alemanha, tendo a Base de Beja como fulcro de uma cooperação que se prolongaria por décadas.

O resultado imediato mais visível na organização do espaço e no arranjo do território foi consequente aos processos de industrialização e de urbanização que, no essencial, assumiram aspectos idênticos aos de outros países de desenvolvimento industrial tardio, em particular, de Espanha e de Itália, apesar do relativo desfasamento. Portugal evidenciava todavia algumas especificidades, de que no plano geográfico se destacaram a industrialização e urbanização difusas, no Norte e Centro Litoral e a escala do crescimento urbano ilegal, sobretudo em torno de Lisboa, o que em parte obstou a que o crescimento de bairros de lata fosse maior no território da capital e da sua periferia imediata.

Ao mesmo tempo, deflagraram as guerras nas colónias africanas que, entre outras consequências, levaram a desvios do investimento público e à alteração da hierarquia de prioridades, o que, por um lado, retardou a moderna infraestruturação do País, que só viria a ter lugar após 1986, com o afluxo das contribuições do Fundo de Desenvolvimento Regional (FEDER) das Comunidades Europeias e, por outro lado, obrigou a que mais de $10 \%$ da população do País emigrasse, pois o crescimento económico, apesar de se fazer a bom ritmo, era insuficiente para o excesso de mão-de-obra que permanecia nos campos, em resultado de 30 anos de políticas ruralistas.

Aqui, também a nossa Geografia, ensino e investigação, permaneceu um tanto à margem, privilegiando, como vimos, o estudo das 'Províncias Ultramarinas' e os temas 'tradicionais' de matriz regional e rural.

De facto, apesar de algumas discussões interessantes em torno dos problemas do desenvolvimento do País - em geral fora das disciplinas curriculares na licenciatura que frequentávamos, apenas dois docentes abordavam no âmbito do seu magistério regular, as questões do desenvolvimento: João Evangelista e Correia da Cunha. Com este fizemos, inclusivamente, algumas visitas de estudo centradas em projectos de desenvolvimento económico territorial: ao Cachão, em Mirandela, ainda em fase de construção, sob a direcção entusiástica de Camilo de Mendonça, o nosso cicerone, e aos planos de rega do Alentejo e 
de Badajoz, o que permitiu confrontar duas experiências e salientar o nosso atraso neste domínio, hoje ainda mais evidente.

Todavia, a coerência metodológica da aprendizagem nas diferentes disciplinas favorecia os argumentos de suporte à 'pureza' da investigação geográfica em detrimento da formação de geógrafos profissionais.

A Geografia teve entretanto uma enorme evolução em Portugal e a maior parte dos jovens licenciados tem encontrado emprego em múltiplas áreas que não a do Ensino. Mas os temas que tanto animaram algumas das discussões desses três estudantes que principiavam o estudo da Geografia, mantêm actualidade: a necessidade de aprofundamento teórico e de desenvolvimento metodológico, a necessidade de circunscrever com rigor (o que não significa limitar) o campo de intervenção dos geógrafos e a necessidade de preparar os profissionais com a capacitação adequada para dar resposta aos desafios com que o País se confronta e que, conforme tem sido evidenciado nos últimos tempos ${ }^{3}$, têm, no essencial, uma dimensão espacial e territorial.

São duas faces da mesma moeda - a teoria e a prática. O seu aprofundamento e articulação permitirão definir o campo de acção da Geografia.

E não há que temer a 'dispersão' dos domínios em que os geógrafos intervêm: o espaço e os territórios estão cada vez mais no âmago das grandes questões do nosso tempo, ou não fossem global, regional e local três palavraschave da contemporaneidade.

3 Tem sido muito interessante verificar como, nos últimos tempos, muitos dos responsáveis pelas propostas de políticas de desenvolvimento-economistas macro, engenheiros-economistas, engenheiros-empresários, fiscalistas, economistas micro, etc-se têm preocupado com questões geográficas... 